squamous cell carcinoma of the mandible: report of two cases. Oral Surg Oral Med Oral Pathol Oral Radiol Endod 2009;108:e54-8.

4. Shivakumar B, Dash B, Sahu A, et al. Basaloid squamous cell carcimoma: a rare case report with review of literature. J Oral Maxillofac Pathol 2014;18:291-4.

\section{A Pedunculated Giant Cutaneous Horn Variant Overlying Invasive Squamous Cell Carcinoma of the Scalp}

Miliana Vojvodic ${ }^{1}$, Kathryn Vanessa Isaac ${ }^{1}$, Ronald Harold Levine ${ }^{1,2}$, Leila Kasrai ${ }^{1,2}$

${ }^{1}$ Division of Plastic and Reconstructive Surgery, Department of Surgery, Faculty of Medicine, University of Toronto, Toronto; ${ }^{2}$ St. Joseph's Health Centre, Toronto, ON, Canada

Correspondence: Miliana Vojvodic

Division of Plastic and Reconstructive Surgery, Department of Surgery, Faculty of Medicine, University of Toronto, 149 College Street, 5th Floor, Room 508, Toronto, Ontario, M5T 1 P5 Canada

Tel: +1-647-823-6230, Fax: +1-416-978-7316

E-mail:m.vojvodic@mail.utoronto.ca

We thank Dr. Janet Malowany, MD FRCP(C) in the Department of Laboratory Medicine at St. Joseph's Health Centre, Toronto, Ontario, Canada for reviewing the histopathology included in this case report.

No potential conflict of interest relevant to this article was reported.

Received: 16 Apr 2016• Revised: 20 Aug 2016• Accepted: 6 Sep 2016 pISSN: 2234-6163 • elSSN: 2234-6171

https://doi.org/10.5999/aps.2016.43.6.618

Arch Plast Surg 2016;43:618-619

Copyright (C) 2016 The Korean Society of Plastic and Reconstructive Surgeons This is an Open Access article distributed under the terms of the Creative Commons Attribution Non-Commercial License (http://creativecommons.org/licenses/by-nc/4.0) which permits unrestricted non-commercial use, distribution, and reproduction in any medium, provided the original work is properly cited.

Giant cutaneous horns $(\mathrm{GCH})$ present as isolated skin lesions with large corneous components of considerable morphologic variation. Despite their striking clinical appearance, prevalence statistics are unknown due to their rarity. Diagnosis of the underlying pathology is essential for appropriate management, as a significant proportion of cutaneous horns arise in the setting of a cutaneous malignancy $[1,2]$.

A morphological variant of a giant cutaneous horn was incidentally discovered on the posterior scalp of a 92-year-old Caucasian female during a hospital admission for a hemorrhagic stroke. The $\mathrm{GCH}$ measured $12 \mathrm{~cm}$ in straight length and $5.4 \mathrm{~cm}$ in base width. The entire lesion was supported by a highly
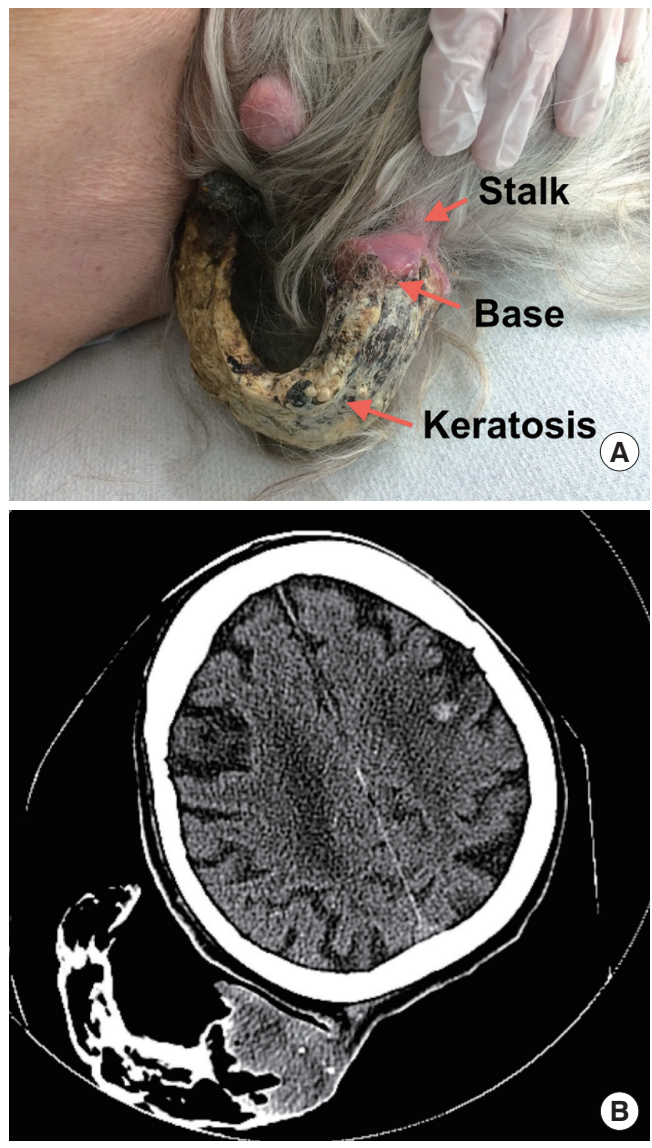

Fig. 1.

(A) Pedunculated giant cutaneous horn based at the occipital scalp. (B) Coronal 2-dimensional computed tomography image showing the lobular giant cutaneous horns base with calcifications attached to subcutaneous tissue by a $1.2-\mathrm{cm}$ stalk.

unusual, mobile cutaneous stalk measuring $1.2 \mathrm{~cm}$ in length and $1.6 \mathrm{~cm}$ in width (Fig. 1A). The onset of growth of the lesion is unknown. The patient had an unremarkable prior medical history. An unenhanced computed tomography scan of the head showed an irregular soft tissue mass attached to the subcutaneous tissues of the posterior scalp without periosteal involvement. Calcifications were noted within the base of the lesion (Fig. 1B). The horn and stalk were excised under local anaesthesia with 0.5 $\mathrm{cm}$ margins, and the defect was closed primarily. A gross cross-section of the base of the CGH showed a hollow core surrounded by ridges of calcific debris and dense keratin (Fig. 2A). Histologic examination of the base showed an invasive squamous cell carcinoma with ulceration corresponding to grade 2 moderately differentiated tumor pathology (Fig. 2B). All surgical margins were negative for malignancy. 

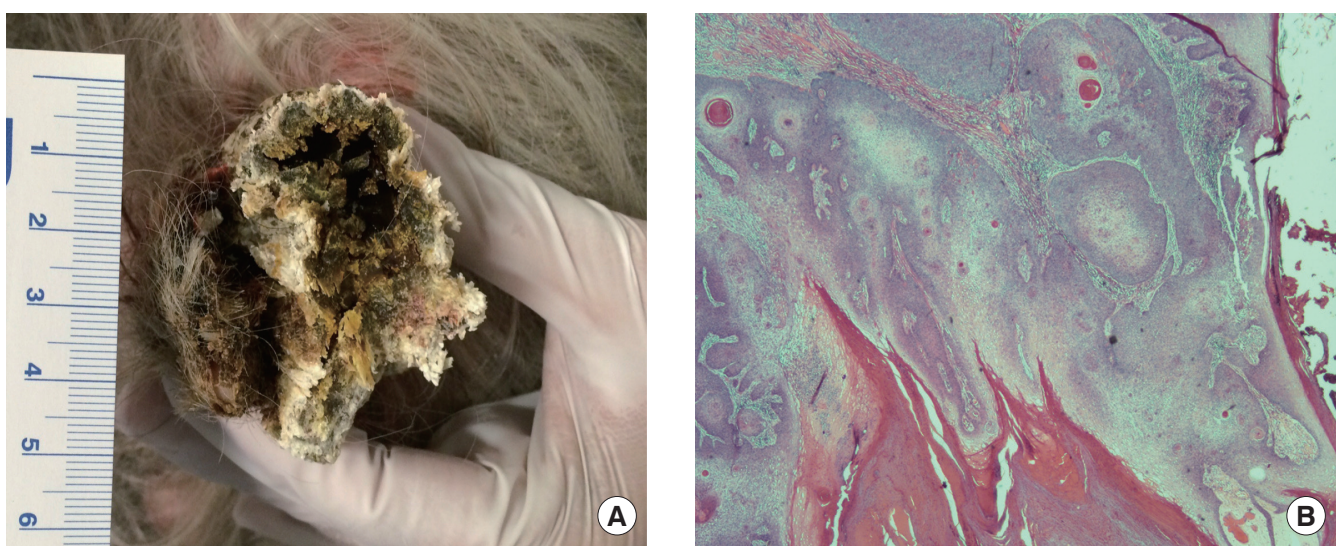

\section{References}

1. Yu RC, Pryce DW, Macfarlane AW, et al. A histopathological study of 643 cutaneous horns. Br J Dermatol 1991;124:449-52.

2. Mantese SA, Diogo PM, Rocha A, et al. Cutaneous horn: a retrospective histopathological study of 222 cases. An Bras Dermatol 2010;85:157-63.

\section{Congenital Multiple Metatarsal Synostoses with Proximal Phalangeal Deformities of the Foot}

Ai Yokoyama, Norio Fukuda, Hirotaka Asato

Department of Plastic and Reconstructive Surgery, Dokkyo Medical University School of Medicine, Shimotsuga, Japan

\section{Correspondence: Ai Yokoyama}

Department of Plastic and Reconstructive Surgery, Dokkyo Medical University School of Medicine, 880 Kitakobayashi, Mibu, Shimotsuga, Tochigi 321-0293, Japan

Tel: +81-282-87-2485, Fax: +81-282-86-1806

E-mail:aiyoko@dokkyomed.ac.jp

No potential conflict of interest relevant to this article was reported.

Received: 24 Feb 2016• Revised: 11 May 2016• Accepted: 24 May 2016 pISSN: 2234-6163 • elSSN: 2234-6171

https://doi.org/10.5999/aps.2016.43.6.619

Arch Plast Surg 2016;43:619-621

Copyright (C) 2016 The Korean Society of Plastic and Reconstructive Surgeons This is an Open Access article distributed under the terms of the Creative Commons Attribution Non-Commercial License (http://creativecommons.org/licenses/by-nc/4.0/) which permits unrestricted non-commercial use, distribution, and reproduction in any medium, provided the original work is properly cited.

Congenital foot abnormalities such as syndactyly, polydactyly, and brachymetatarsia are commonly seen by plastic surgeons. There have been reports of cases of congenital synostosis of the foot, with the majority of cases involving the rear foot and midfoot
(Boccio et al. [1]). However, to the best of our knowledge, multiple metatarsal synostoses with proximal phalangeal deformities is extremely rare and independent from any syndromes and congenital anomaly patterns.

A 28-year-old woman was referred to our plastic surgery outpatient clinic with a chief complaint of pain and deformity in her right forefoot. There were deformities of the right fourth and fifth toes, making it difficult for her to purchase ready-made heeled shoes. The patient had a history of depression, but it was controlled with no adverse effects on her daily life. No other relevant past history or family history was present. A clinical examination demonstrated abducted fourth and fifth toes, and the interdigital side of the first toe and the dorsal sides of the fourth and fifth toes had callosities (Fig. 1). The left foot was normal in all respects.

Radiographs showed metatarsal synostoses from the third to the fifth metatarsal bones, and the third metatarsophalangeal joint was comprised of the third and fourth proximal phalanges and the third metatarsal bone (Fig. 2). In this case, dysfunction was not severe, and a minimally invasive operation was planned.

The operation was performed using an open method. First, the extensor tendons of the fourth toe were kept; then a wedge osteotomy at an angle of 30 degrees was performed, followed by abduction and reduction of the shaft of the fourth proximal phalanx. perforated and fixed by crossing soft wire using the two-dimensional intraosseous wiring technique (Moriya et al. [2]). This technique provides stronger fixation between the bones with its tension band function.

Titanium plate fixation was added on the lateral side of the proximal phalanx to ensure more reliable Finally, the lateral surfaces of the bones were
Fig. 2.

(A) Cross-section of the giant cutaneous horns (GCH) showing hollowing of conical component with surrounding parakeratosis, calcific debris and keratin. Ruler markings in centimeters. (B) $H \& E$ stained section $(\times 100)$ of the $\mathrm{GCH}$ base with moderately differentiated squamous cell carcinoma. 